\title{
The Impact of Prestressed die Construction with Cemented Carbide Insert on Stress Distribution During Extrusion
}

\author{
Stanisław Kut ${ }^{1, *}$, Irena Nowotyńska ${ }^{2}$ \\ Rzeszow University of Technology, The Faculty of Mechanical Engineering and Aeronautics, Department of Materials Forming and Processing, Al. \\ Powstańców Warszawy 8, 35-959 Rzeszów, Poland \\ Rzeszow University of Technology, The Faculty of Management, Department of Computer Engineering in Management, Al. Powstańców Warszawy \\ 8, 35-959 Rzeszów, Poland
}

\begin{abstract}
An important parameter for optimizing tool life is the introduction of a precompression stress in the die insert through the use of the compression ring. The tests were carried out for a die with a cemented carbide insert. Three die construction solutions were used in the tests. They differ by the ratio of the wall thickness of the die insert to the wall thickness of the compression ring $g_{m} / g_{p}=(0.57 ; 1 ; 1.75)$ while maintaining a constant tool diameter. All construction solutions using cemented carbide insert were analysed for three values of mounting interference amounting to $\delta=(0.004 ; 0.008 ; 0.016) \mathrm{mm}$. On the basis of the results obtained, the degree of impact of the parameters examined (the interference value $\delta$ and the ratio $g_{m} / g_{p}$ ) on the distribution and level of circumferential stress in a die compressed by a single ring using a cemented carbide insert were determined. It was shown that the size of the interference and the quotient $\left(g_{m} / g_{p}\right)$ had the great impact on the reduction of working stresses in the die insert.
\end{abstract}

Keywords: extrusion; die compressed; cemented carbide insert; stress distribution

\section{Introduction}

The extrusion process has its advantages, but requires the use of precise calculation methods to achieve specific technological goals. Extrusion is characterized by high deformation values, large unit pressures on the tool surface, often complex geometry of the product. In this technology, in addition to giving the right shape of the product, it is necessary to take into account the economically justified life of the tool. The tool with such large unit pressures is exposed to wear on the work surface, elastic deformation and cracking. The life of the dies depends on their proper design and execution, taking into account the appropriate thermal and chemical treatment and the mechanical response to the material selected, the sequence of individual heat treatment operations, and the conditions under which the extrusion itself runs (tool temperature, insert geometry, process speed, type and amount of lubricant providing optimal tribological conditions). Another important parameter is the type of tool material used.

Because of the high unit pressures, the effort of the die material is often so high that it leads to premature wear and even destruction. Information on a tool life is particularly important when dealing with issues related to increasing the efficiency of the extrusion process. The literature [1-14] provides research on the impact of various parameters on tool life, including compressed dies. Gorenbaek et al. [1] proposed a 
versatile pre-stressing mechanism which can produce desirable compressive stress to prolong die life in forging. Saroosh et al. [2] studied the effect of the flow stress and strain-hardening of forged materials for predicting the service life of forging tools, whereas Lee et al. [3] investigated the effects of different shrink fitting ratios for predicting the fatigue life of die insert. Yurtdas et al. [4] studied the use of carbon fibre composite material for the shrink ring to improve the tool life. Meanwhile, Kawahara et al. [5] proposed the use of master fatigue diagram to predict the fatigue life of die insert. This method showed good agreement in predicting the fatigue life of a 3-point bending test specimen. In this paper [6], the authors extend further the use of master fatigue diagram to improve fatigue life by proposing a method to determine optimal shrink fitting ratio for the 2-layer compound forging die in simple axisymmetrical forging [7]. The die set structural analysis problem is formulated as a contact problem with both shrink fit and preloaded clamping considered, solved iteratively by a varying penalty method. In the work [8] the method of calculating the interference between the rings and the insert in pre-compressed dies with two outer and inner rings was given.

In the work [9] the stress analysis and design of a pre-stressed cold extrusion die with stress rings was carried out. The calculation of the contact pressure on the interface between the die insert and stress ring was included. In this method, an elastic finiteelement method and Lamé's equation were used for the analyses of the die insert and the stress ring, respectively. The cold extrusion process was simulated by the rigid finite-element method.

In this research [10], sintered carbide is considered as the materials of the first stress ring to increase the stiffness of the pre-stressed die. In order to evaluate the validation of this method, FE-analysis was performed according to the arrangement of die configurations. The analysis showed that the backward extrusion die pre-stressed with the high stiffness material could be more strengthened than the conventional die construction. Similarly, in the work [11] the rigid-plastic FE analysis of backward extrusion process using DEFORM was performed and the analysis of elastic deformation of the dies was done by using ANSYS with non-linear contact. In the simulation results, it was found that the use of high stiffness materials to the first stress ring of forging dies could reduce the elastic deformation of die insert without failure.

The paper presents the results of comparative analysis of circumferential (assembly and operating) stresses in pre-compressed dies with one steel ring. The dies with cemented carbide insert with different ratio of die insert thickness and pre-stressing ring were tested using three values of assembly interference. The impact of die design was analysed by using three variants of the thickness of the die insert and the compression ring, and the impact of mounting interference on the distribution and value of the circumferential stress in the die insert and compression ring after assembly and during extrusion.

\section{Numerical modeling of the extrusion process}

The analysed die with dimensions is shown in Figure 1. The angle of the work cone is assumed as $\alpha=30^{\circ}$, while the length of the calibration belt $\mathrm{I}_{\mathrm{k}}=5 \mathrm{~mm}$.

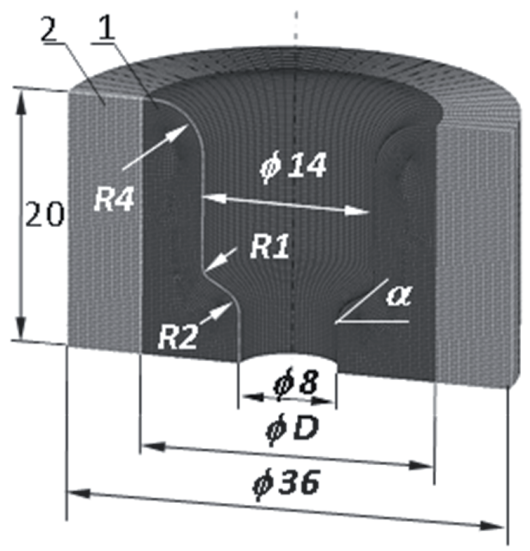

Figure 1: Diagram of the die with dimensions (1- die insert, 2-compression ring).

Numerical calculations of the extrusion process were made using the commercial MARC/Mentat software from MSC Software. Three die design solutions were used in the tests, differing by the ratio of the wall thickness of the die insert to the wall thickness of the compression ring $g_{m} / g_{p}=(0.57 ; 1$ and 1.75) while maintaining a constant tool diameter (Fig. 2). All construction solutions using a cemented carbide insert were analysed for three values of mounting interference amounting to $\delta=(0.004$; 0.008 and 0.016$) \mathrm{mm}$. The tests were carried out to 
determine the effect of the quotient of the insert wall thickness to the thickness of the compression ring, as well as the amount of interference between the insert and the ring on the value of assembly and working stresses in the die. The stress was measured for the insert at points $A, B, C$ and $D$ and the ring at points $E, F$ and $G$ (Fig. 2). The assembly stresses resulting from insert insertion and the compression ring as well as stresses during the extrusion process were analysed.

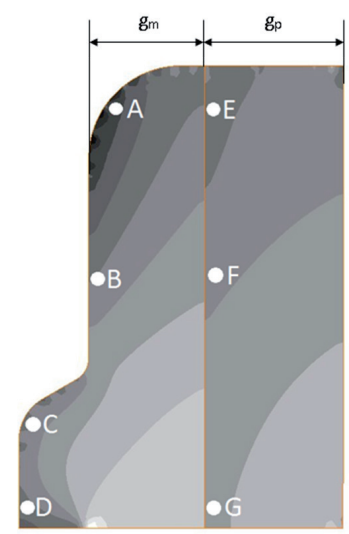

Figure 2: Locations of measurement points of circumferential stresses.

To determine the assembly insert $\delta$, the following formula was applied:

$$
\delta=\frac{D_{z w}-D_{w p}}{2}
$$

where: $D_{z w}$ - outer diameter of the die insert, $\mathrm{mm}$; $D_{w p}$ - inner ring diameter, $\mathrm{mm}$.

A two-dimensional geometric model of the extrusion process was built, which was analysed assuming axial symmetry (axi-symmetrical model). An exemplary model expanded to 3D form with contact conditions of deformable bodies is shown in Figure 3.

The Hooke model was used to describe the properties of the deformable material in the elastic range of the die insert and the compression ring. The mechanical properties of the compression ring made of NC10 steel were described with $\mathrm{E}=210000 \mathrm{MPa}$ and $v=0.3$. The material properties of the die insert made of cemented carbide G30 were taken from [15] and were $E=590000 \mathrm{MPa}$, $v=0.2$. The properties of the extruded material were described using a model of elastic-plastic body with

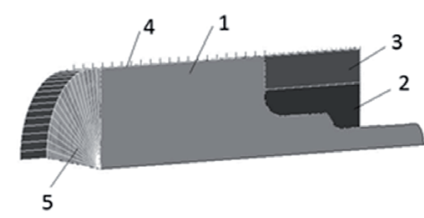

Figure 3: Exemplary geometrical model of the analysed extrusion process: 1-formed material, 2 - die insert, 3 - prestressing ring, 4 - container surface, 5 - punch surface.

non-linear reinforcement. The values of determined material constants for the extruded material and the parameters of the strain curve are taken from the literature [16] and given in table 1. The friction model is described by Coulomb's law. The coefficients of kinetic friction between the extruded material and the rigid surfaces of the punch and container as well as the deformable die were assumed to be 0.3 [17]. However, the coefficient of static friction between the die insert and the compression ring was 0.14 [18].

Table 1: Values of mechanical test materials.

\begin{tabular}{|l|l|l|l|}
\hline Material & $\begin{array}{l}\text { Tensilestrength } \\
M P a\end{array}$ & $\begin{array}{l}\text { Young's modulus } \\
\text { E,MPa }\end{array}$ & $\begin{array}{l}\text { Poisson's coefficient } \\
\boldsymbol{V}\end{array}$ \\
\hline $\begin{array}{l}\text { Lead } \\
(99.98 \%)\end{array}$ & 15 & 18000 & 0.42 \\
\hline
\end{tabular}

Class 4 type 10 elements - axisymmetric ring quadrilateral [19] used to construct the finite element mesh of the deformed material. Numerical simulation was carried out using the global remeshing option. The size of the elements of the die insert and the compression ring was about $0.25 \mathrm{~mm}$, while the extruded material averaged about $0.4 \mathrm{~mm}$, while the mesh was additionally compacted in the area of contact of the extruded material with the die. The evolution of the surface of plasticity as a result of the phenomenon of strain hardening was described using the isotropic model. In the calculations the Huber-Mises-Hencky plasticity condition, the associated law of plastic flow of Prandtl-Reuss and the implicit scheme of integration of differential equations over time with the Newton-Raphson method were used.

\section{Results and Discussion}

Figure 4 shows the dependence of the values of initial circumferential stresses after assembly at measuring points ( $, B, C$ and $D$ ) lying in the area of the die insert depending on the value of $g_{m} / g_{p^{\prime}}$ as well as the value of the interference. 


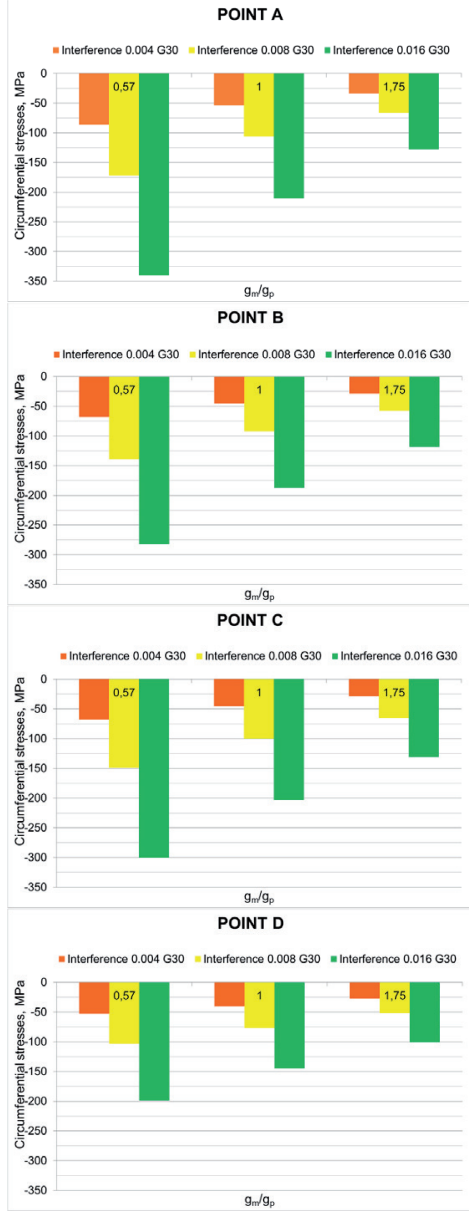

Figure 4: The value of initial circumferential stress at points A-D of the die after assembly depending on the value of $g_{m} / g_{p}$ for the cemented carbide insert and three mounting interference.

When comparing the obtained values of initial circumferential stresses after assembly for the examined cases shown in Figure 4, it was noticed that favourable circumferential compressive stresses (negative values) appear with all the measuring places of the die insert as the pressure increases. At all analysed measuring points (A-D), their value is higher the greater the mounting interference. The ratio of $g_{m} / g_{p}$ also has the significant impact on the value of assembly stress. The data on the diagrams (Fig. 4) show that at all measuring points (A-D), along with the increase of $g_{m} / g_{p^{\prime}}$ the value of favourable circumferential compressive stresses decreases. This trend occurs regardless of the size of the mounting interference. Therefore, in the examined range of parameters, the theoretically the most beneficial effect in the form of the highest values of circumferential compressive stresses in a carbide die insert can be obtained by using the largest possible mounting pressure and the smallest value of the $g_{m} / g_{p}$ quotient. The least favourable due to the value of the initial circumferential compressive stress in the examined range of parameters is the use of the smallest interference value, i.e. $0.004 \mathrm{~mm}$ and the largest quotient $\mathrm{g}_{\mathrm{m}} / \mathrm{g}_{\mathrm{p}}=1.75$.

Figure 5 shows the calculated values of the initial circumferential stresses occurring after mounting the die insert and the ring at the measuring points $\mathrm{E}-\mathrm{G}$ located in the area of the compression ring.

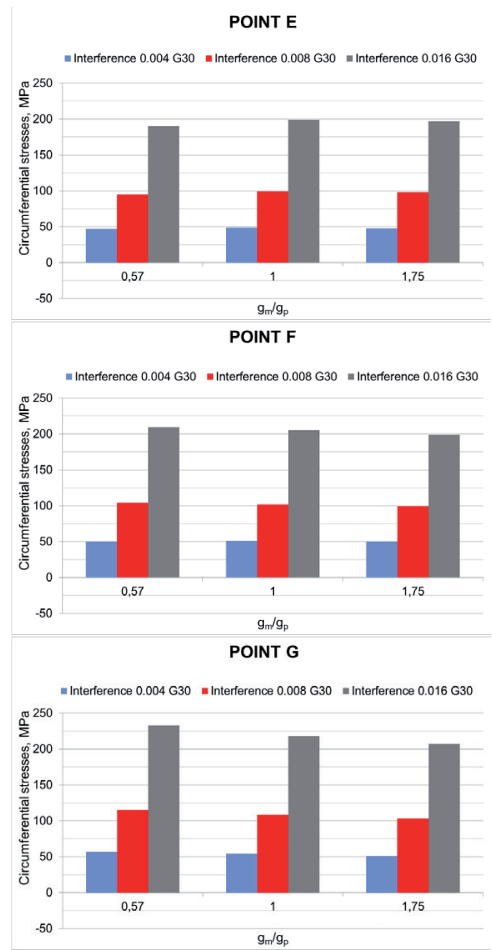

Figure 5: The value of initial circumferential stresses at the E-G points of the ring after assembly depending on the value of $g_{m} / g_{p}$ for a cemented carbide insert and three mounting interference.

In the case of the ring, the circumferential assembly stress is tensile at all measuring points and increases as the interference value increases. As it results from the distribution of stress values on individual charts (Fig. 4), the influence of the $g_{m} / g_{p}$ parameter on the value of circumferential tensile stress in the compression ring after assembly is basically small. 
The diagrams (Fig. 6) show the values of circumferential stress under load at A-D measuring points belonging to the die insert during extrusion using the three tested interference values and three values of the ratio $g_{m} / g_{p}$.

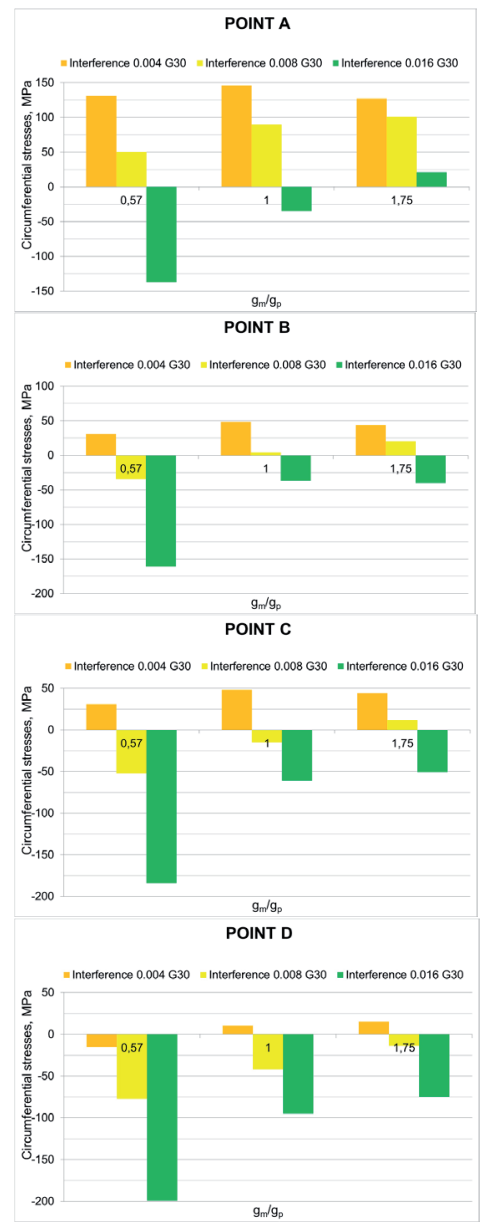

Figure 6: The value of the working circumferential stress at points A-D of the die during extrusion depending on the value of $g_{m} / g_{p}$ for the cemented carbide insert and three mounting interference.

In the case of the largest of the tested impacts for the ratio of $g_{m} / g_{p}$ of 0.57 and 1 , the values of these stresses are negative, which means that the value of the tensile circumferential operating stresses in the die is less than the values of the circumferential compressive stresses after assembly of the insert and the compression ring. The ratio of $g_{m} / g_{p}$ has the significant impact on the value of working stress in the die insert, the lower the value of this quotient, the more favourable (Fig. 6).

When analysing the distributions and values of ring stresses in the ring during extrusion (Fig. 7), it can be clearly seen that the efficiency of using the compression ring is the higher, the greater the value of the mounting interference. However, the value of the $\mathrm{gm} / \mathrm{gp}$ at the analysed $\mathrm{E}-\mathrm{G}$ measuring points of the compression ring practically does not affect the value of working stresses at the selected measuring points of the compression ring.

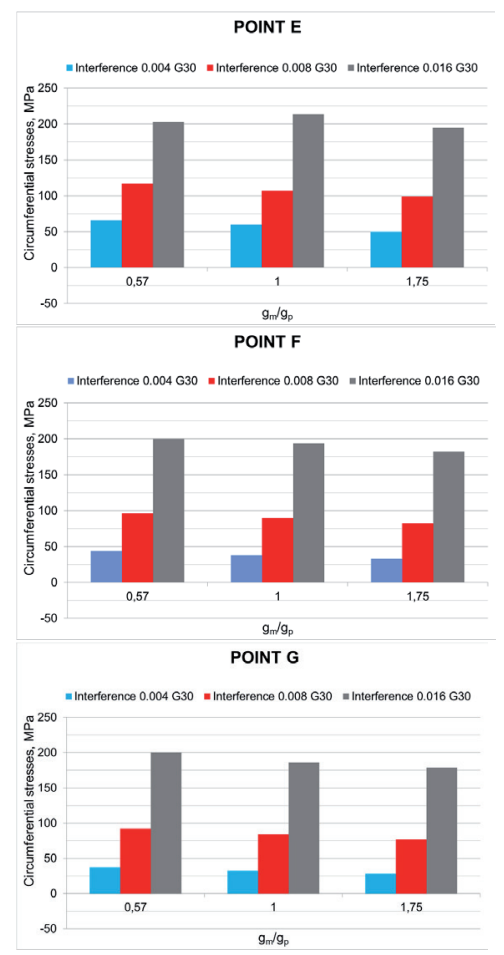

Figure 7: The value of working circumferential stresses at the $\mathrm{E}-\mathrm{G}$ points of the ring during extrusion depending on the value of $g_{m} / g_{p}$ for the cemented carbide insert and three mounting interference.

When considering strength and tool life, in addition to the values of circumferential stresses analysed at selected measuring points, the distributions and gradients of these stresses on the longitudinal section of the die insert and the pre-stressing ring are important. The examples of circumferential stress distribution on the longitudinal section of the die insert and the compression ring of the interference value of $0.008 \mathrm{~mm}$ and three values of the $g_{m} / g_{p}$ quotient are shown in Figure 8 for the post-assembly variant and for the variant under load. 


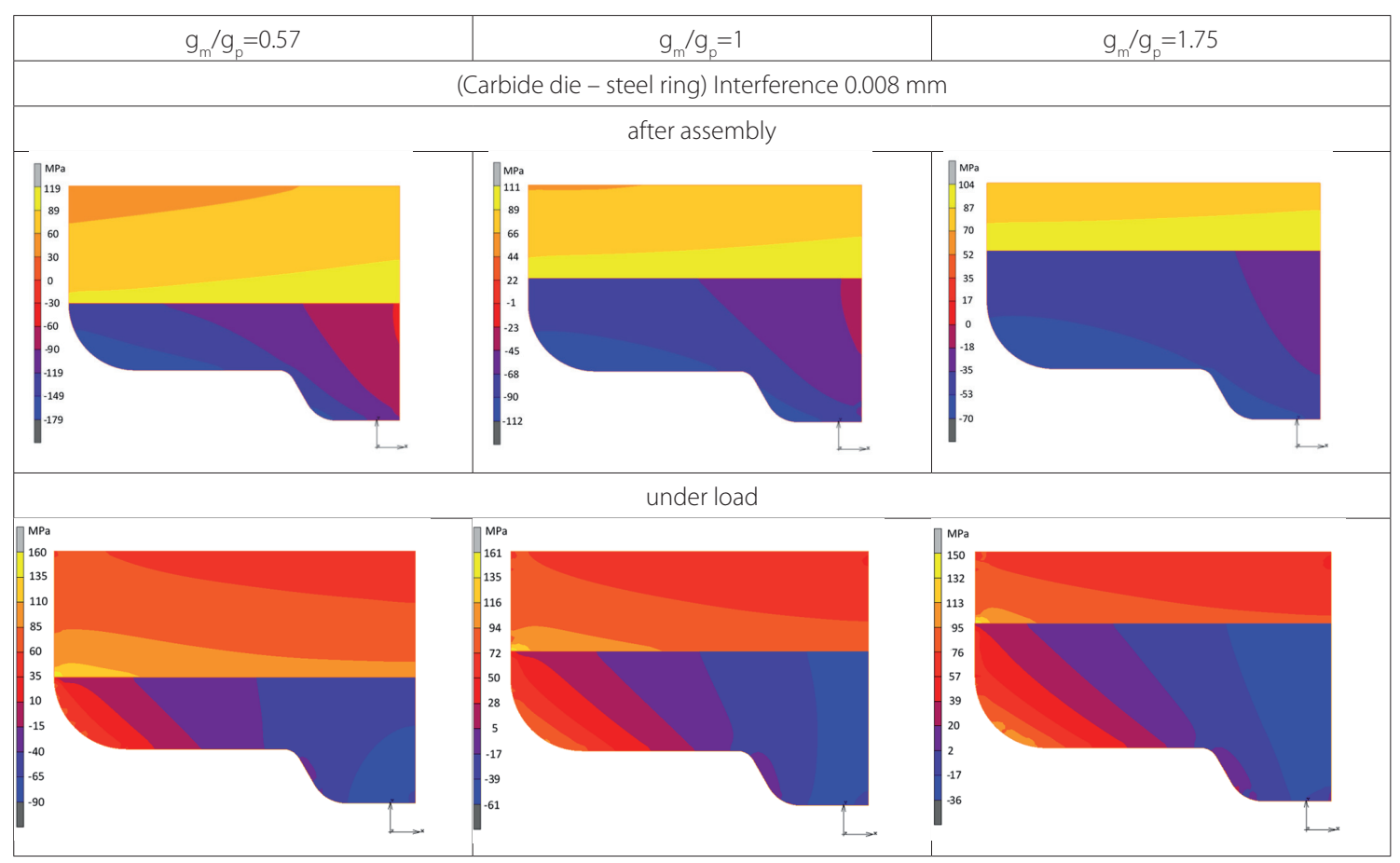

Figure 8: Distributions and values of circumferential stresses in the die after assembly and under load with an interference pressure of $0.008 \mathrm{~mm}$ for three $\mathrm{g}_{\mathrm{m}} / \mathrm{g}_{\mathrm{p}}$ values of $0.57,1$ and 1.75 .

The circumferential tensile stress in the insert and the ring after assembly are relatively homogeneous (i.e. without significant gradients) and their distribution depends on the ratio of gm/gp. This in turn has the greater impact on stress values than their distribution. It is similar under load except that both in the case of the insert and the ring, the stresses are less uniform and the areas of their concentration can be determined. Regardless of the ratio of $g_{m} / g_{p}$ the largest stress concentration occurs at the insert corner from the extruded material entry side and in the area of the inner corner of the compression ring also from the extruded metal input side to the die.

In engineering practice, when selecting the interference in the case of an insert and a compression ring, it should be ensured that during loading, have occurred the smallest possible stress gradients. In addition, that the values of circumferential tensile stress in the ring do not exceed the allowable values. For carbide inserts, the value of these stresses is limited and amounts not more than $600 \mathrm{MPa}$ [20]. Therefore, it is important to search for solutions, including geometric ones, to reduce stress values as adversely as possible.

\section{Conclusions}

The tests showed the significant impact of all tested parameters (i.e. the size of the mounting interference and the ratio of $g_{m} / g_{p}$ ) on the level of circumferential stresses in the die both during assembly and working during extrusion.

1. In all the cases examined, the use of mounting interference causes the creation of a die insert with favourable initial circumferential compressive stresses. The value of these stresses preferably increases in the direction of negative values as the assembly pressure increases, and the intensity of this increase decreases as the value of $g_{m} / g_{p}$ increases.

2. Regardless of the interference value applied, the value of the circumferential stress in the die insert is very favourably influenced by the die geometric system expressed by the ratio $g_{m} / g_{p}$. In the range examined, as the value of this parameter decreases, the favourable stresses in the insert increase, with the quotient $\left(g_{m} / g_{p}\right)=0.57$ being the most favourable among those tested.

\section{References and Notes}

[1] Groenbaek J., Lund E. (2008) Tool Optimization by Means of Effective Prestressing System. Conference Asia Forge, New Delhi, India.

[2] Saroosh M. A., Lee H. C., Im Y.T., Choi S.W., Lee D.L. (2007) High cycle fatigue life prediction of cold forging tools 
based on workpiece material property. Journal of Material Processing Technology 191, 178.

[3] Lee H.C., Saroosh M. A, Song J.H., Im Y.T. (2009) The effect of shrink fitting ratios on tool life in bolt forming processes. Journal of Material Processing Technology 209, 3766.

[4] Yurtdad U., Ince C., Kilicaslan H. Yildiz (2017) A case study for improving tool life in cold forging: carbon fiber composite reinforced dies. Journal of Research on Engineering Structures and Materials 3-1, 65.

[5] Kawahara J., Matsumoto R., Mori S., Osakada K. (2011) Predicting fatigue life of carbide tool using elastic-plastic FEM, Proceedings of the 44th International Cold Forging Group Plenary Meeting, 55.

[6] Wang Ch., Kam H., Wang X. (2018) Determination of shrink fitting ratio to improve fatigue life of 2-layer compound forging die by considering elasto-plastic deformation of outer ring. Procedia Manufacturing 15, 481.

[7] Joun M.S., Lee M.C., Park J.M. (2002) Finite element analysis of prestressed die set in cold forging. International. Journal of Machine Tools \& Manufacture 42, 1213.

[8] Zimpel J. (1996) Obliczanie matryc wzmacnianych jednym pierścieniem. Obróbka Plastyczna Metali 2, 43.

[9] Yeo H. T., Choi Y., Hur K. D. (2001) Analysis and Design of the Prestressed Cold Extrusion Die. International. Journal Advanced Manufacturing Technology 18, 54.

[10] Hur K. D., Choi Y., Yeo H-T. (200) Design for stiffness reinforcement in backward extrusion die. Journal of Materials Processing Technology 130-131, 411.

[11] Hur K. D., Choi Y., Yeo H.T. (2003) A design method for cold backward extrusion using FE analysis Finite Elements in Analysis and Design 40 (2), 173.

[12] Frater J. L. (1989) Application of Finite Element Methods to the Design of Prestressed Tooling, Journal Mater. Shaping Technology 7, 49.

[13] Lange K. (1985) On the stress distribution in prestressed extrusion dies under non-uniform distribution of internal pressure. International Journal of Mechanical Sciences 27 (3), 169.

[14] Gronostajski Z, Hawryluk M., Jaśkiewicz K., Niechajowicz A., Polak S., Walczak S., Woźniak A. (2007) Wpływ tolerancji wykonawczych matryc sprężanych do wyciskania na ich wytężenie. Plasticita materialov 14, 87

[15] Cwajna J., Roskosz S. (2001) Effect of microstructure on properties of sintered carbides Materials Characterization 46, 197.

[16] Pater Z. (2003) Ołów jako materiał modelowy do symulacji procesów obróbki plastycznej na gorąco Obróbka Plastyczna Metali 4, 41.

[17] Kut S., Nowotyńska I. (2011) Comparative numerical analysis of die wear during extrusion process of metals with different properties. Hutnik - Wiadomości Hutnicze 11, 925.

[18] https://www.engineeringtoolbox.com

[19] MSC Software: (2014) MSC. Marc Volume B: Element Library.

[20] Zimpel J. (2002) Obliczanie matryc wstępnie sprężonych dwoma pierścieniami. Obróbka Plastyczna Metali 3, 41. 